\title{
Caracterização mecânica e reológica de concretos com resíduos de madeira e sílica ativa
}

\section{Mechanical and rheological characterization of concretes with sawdust and silica fume}

\author{
${ }^{1}$ Lucas Massarotto, ${ }^{2}$ Alex Neves Junior, ${ }^{3}$ João Augusto Dunck Dalosto \\ ${ }^{1}$ Graduado em Engenharia Civil (UFMT) (lucasmassarotto@gmail.com) \\ ${ }^{2}$ Doutor em Engenharia Civil (UFRJ), Professor Adjunto IV do Departamento de Engenharia Civil - \\ Universidade Federal de Mato Grosso (alexnevesjr@gmail.com) \\ ${ }^{3}$ Mestre em Desenvolvimento e Planejamento Territorial (PUC Goiás), Professor da Faculdade de Ciências \\ Agrárias, Biológicas e Sociais Aplicadas - Universidade do Estado de Mato Grosso (dunckdalosto@ gmail.com)
}

\begin{abstract}
RESUMO: O concreto é um dos materiais de construção mais utilizados no mundo, mas devido ao seu processo de produção, tem um grande impacto ambiental pelas atividades relacionadas a fabricação e extração de matériaprima. A presente pesquisa tem por objetivo analisar os efeitos da incorporação dos resíduos de madeira e sílica ativa no concreto a partir da substituição parcial da areia (agregado miúdo) por resíduos de serragem e do cimento Portland por sílica ativa, para produção de concreto com propriedades mecânicas e reológicas satisfatórias. Desta forma, foram produzidas amostras de concreto com substituição parcial de areia por serragem em 5\%, 7,5\% e 10\% do peso total da areia na mistura de referência e, também, amostras de concreto com as mesmas porcentagens de substituições, porém, conjuntamente, com substituição parcial do cimento por sílica ativa em $10 \%$ do peso total de cimento. Após a fabricação das seis amostras, foram realizados ensaios de slump test, de absorção por capilaridade e ensaio de compressão simples, com intuito de verificar as variações nas propriedades reológicas e mecânicas em relação ao concreto de referência, constituído por mistura convencional com agregados de areia, brita e cimento. Os resultados apontam que o uso de serragem na matriz cimentícia gera redução da densidade de concreto, funcionando como aditivo retardador natural de pega e, também, produz um concreto com porosidade e propriedades mecânicas satisfatórias em relação ao concreto de referência. Além disso, a sílica ativa controlou a trabalhabilidade e a absorção de água por capilaridade quando comparado ao concreto de referência. Conclui-se, portanto, que os as referidas substituições geram efeitos benéficos no comportamento reológico e mecânico do concreto quando comparado com a mistura de referência.
\end{abstract}

Palavras-chave: Concreto; Ensaio de Compressão simples; Slump test.

\begin{abstract}
Concrete is one of the most used construction materials in the world, but due to its own production process, it has a great environmental impact by the activities regarding to the raw material extraction and cement manufacturing. The present research has the objective of analyzing the effects of the incorporation of sawdust and silica fume residues in the concrete from the partial replacement of the sand (small aggregate) by sawdust residues and Portland cement by silica fume, for the production of concrete with reasonable mechanical properties and rheological conditions. In this way, concrete samples were produced with partial replacement of sand by sawing in 5\%,7.5\% and $10 \%$ of the total weight of the sand in the reference mixture, as well as concrete samples with the same percentages of substitutions, together with partial replacement of the cement with silica fume in $10 \%$ of the total weight of cement. After the six samples were manufactured, the slump test, capillary absorption test and simple compression test were applied in order to verify the variations in the rheological and mechanical properties in relation to the reference concrete, which consist of conventional mixing with aggregates of sand, gravel and cement. The results indicate that the use of sawdust in the cement matrix generates reduction of concrete density, acting as a natural retardant additive, and also produces a concrete with satisfactory porosity and mechanical properties related to the reference concrete. In addition, the active silica controlled the workability and water absorption by capillarity when compared to the reference concrete. It is therefore concluded that the said substitutions generate considerable effects on the rheological and mechanical behavior of the concrete as compared to the reference mixture.
\end{abstract}

Keywords: Concrete; Compression Test; Slump test, Sawdust, Capillarity 


\section{INTRODUÇÃO}

De acordo com a Sindicato Nacional da Indústria do Cimento - SNIC, em 2016, foram produzidas 57 milhões de toneladas de cimento. Em 2019, só no mês de abril, foram comercializadas 4,4 milhões de toneladas de cimento (SNIC, 2019). Como as matérias-primas envolvidas na fabricação do concreto são extraídas da natureza, o aumento do impacto ambiental causado por essa cadeia produtiva tem sido cada vez mais significativo ao longo do tempo. Em vista disso, no Brasil e no mundo, cresce cada vez mais a necessidade de novas alternativas para minimizar os impactos causados à natureza em decorrência da aplicação e utilização do concreto (ABCP, 2013).

A construção civil é um setor que causa grande impacto ambiental, protagonizando a geração de resíduos de toda a sociedade (SENAI et al., s/d). De acordo com a Associação Brasileira de Empresas de Limpeza Pública e Resíduos Especiais - ABRELPE, em 2014 foram coletadas no Brasil, 122.262 toneladas de resíduos por dia (ABRELPE, 2014)

O termo "concreto ecológico" tem sido usado para designar a incorporação de resíduos gerados por diversas atividades humanas, entre elas a da própria indústria da construção civil, com o objetivo de minimizar o consumo de cimento e agregados para execução de novas obras, por exemplo, os resíduos de madeira e a sílica ativa. A resolução no 307 de 2002 do Conselho Nacional do Meio Ambiente considera que os geradores de resíduos da construção civil devam ser responsáveis pela destinação dos seus próprios resíduos (CONAMA, 2002).

A sílica ativa é um pó fino pulverizado obtido do processo de fabricação do silício metálico ou ferro silício. As partículas deste material são esféricas e possuem um diâmetro médio menor do que $1 \mu \mathrm{m}$ (TECNOSIL, 2018). Assim, este material potencial para ser utilizado como um elemento de adição, uma vez que suas partículas são menores que os grãos de cimento e, dependendo do grau de dispersão, podem preencher melhor os vazios, tornando o concreto mais denso. Desta forma, a adição de sílica ativa pode garantir menor permeabilidade, diminuição da exsudação em estado fresco e, também, resistência (DIPROTEC, 2016).

Já a serragem, por ser um material fibroso e natural, proveniente da madeira, a sua adição em qualquer material de propriedades pozolânicas é de fundamental importância, visto que pode garantir a durabilidade em meios extremamente alcalinos, como o encontrado nas matrizes cimentícias. Desta forma, quando o pó de serra é utilizado em substituição parcial ao agregado miúdo, este possibilita a redução da areia na produção de blocos de concreto para vedação e/ou elementos de enchimento de pré-lajes, comportando-se como um material mais leve e, também, de forma isolante, em função da baixa condutividade térmica. Destaca-se ainda que quando este material é utilizado na composição do traço de materiais de acabamento, este também melhora a absorção sonora (SANTOS, 2014).

Considerando a forte tendência de fabricação de materiais voltados à sustentabilidade e o forte impacto da construção civil no meio ambiente, mostra-se importante indagar: a substituição parcial - de componentes do traço do concreto - por serragem e/ou sílica ativa geram efeitos benéficos nas características mecânicas e reológicas do concreto? Evidências apontam que, de fato, estes materiais geram efeitos na resistência à compressão, absorção de água, tempo de cura do concreto e, portanto, é nesse sentido que a hipótese do estudo foi configurada.

Isto posto, o presente estudo objetiva analisar os efeitos da incorporação dos resíduos de madeira e sílica ativa no concreto a partir da substituição parcial da areia (agregado miúdo) por resíduos de serragem e do cimento Portland por sílica ativa. Busca-se encontrar uma alternativa para a utilização destes materiais para produção de misturas que gerem concreto com propriedades mecânicas e reológicas satisfatórias, quando comparadas a do concreto de referência e, desta forma, evidenciando uma potencial destinação para resíduos advindos de 
outras produções.

\section{MATERIAL E MÉTODOS}

\subsection{Materiais utilizados}

Para elaboração dos concretos, foram utilizados: cimento Portland Ciplan CP II-Z-3, agregado graúdo, miúdo, sílica e serragem. O cimento foi acondicionado em laboratório, ensacado e apoiado em estrado de madeira, evitando desta forma que estes entrassem em contato com umidade.

Os agregados graúdo e miúdo foram previamente secos antes de serem utilizados nas misturas uma vez que estavam expostos a céu aberto. A granulometria de cada material foi analisada conforme a NBR 7181 (ABNT, 2018a), caracterizando-se para o agregado graúdo britado com dimensão média entre 4,8 a $19 \mathrm{~mm}$ e, a areia grossa com granulometria acima de $2 \mathrm{~mm}$ e abaixo de $1,2 \mathrm{~mm}$.

A sílica utilizada se caracteriza como material menor que 0,6 mm (ABNT, 1984), enquanto a serragem, como material passante pela peneira 3/8" (abertura nominal de $9,5 \mathrm{~mm}$ ) (ABNT, 1984). Esse resíduo foi gerado na confecção de caibros e pranchas, sendo estes provenientes da serragem de madeiras de lei.

\subsection{Definição do traço}

Os concretos foram elaborados considerando um traço inicial de 1:0,5:0,5 (cimento: agregado miúdo: agregado graúdo) com relação "água/material cimentício" igual a 0,5. Foram realizadas sete moldagens, divididas em três etapas:

1. Inicialmente, moldou-se o traço de referência com o traço indicado anteriormente; Nesta etapa, produziu-se quatro corpos de prova sem o uso da sílica e serragem;

2. A partir do traço de referência, em um segundo momento, foram produzidos traços com substituição parcial de 5\%,7,5\% e $10 \%$ da massa total da areia por serragem; Nesta etapa, também foram moldados quatro corpos de prova para cada substituição indicada;

3. Por último, para cada um dos traços de substituição citados anteriormente, substituise $10 \%$ de cimento por sílica ativa para cada uma das três porcentagens de substituição por serragem; para estes, foram confeccionados três corpos de prova em cada dosagem.

Na Tabela 1 estão dispostas as diferentes famílias de concretos confeccionados e as porcentagens de substituição utilizadas em cada caso. Todos os concretos foram confeccionados utilizando corpos de prova nas dimensões cilíndricos de $10 \mathrm{~cm} \mathrm{x} 20 \mathrm{~cm}$ (ABNT, 1993).

Tabela 1 - Resumo dos traços de concreto pesquisados

\begin{tabular}{l|l|l|l|l}
\hline COMPOSIÇÃO & TRAÇO & RELAÇÃO A/C & SERRAGEM (\%) & SÍLICA (\%) \\
\hline Referência & $1,0: 0,5: 0,5$ & 0,5 & - & - \\
\hline S 5\% & $1,0: 0,5: 0,5$ & 0,5 & 5 & - \\
\hline S 7,5\% & $1,0: 0,5: 0,5$ & 0,5 & 7,5 & - \\
\hline S 10\% & $1,0: 0,5: 0,5$ & 0,5 & 10 & - \\
\hline SS 5\% & $1,0: 0,5: 0,5$ & 0,5 & 5 & 10 \\
\hline SS 7,5\% & $1,0: 0,5: 0,5$ & 0,5 & 7,5 & 10 \\
\hline SS 10\% & $1,0: 0,5: 0,5$ & 0,5 & 10 & 10 \\
\hline S= Serragem; SS= Serragem + Sílica
\end{tabular}


A Tabela 2 apresentam as quantidades em massa dos materiais que foram utilizados para a confecção dos corpos de prova.

Tabela 2 - Resumo em massa, traços de concreto pesquisados

\begin{tabular}{c|c|c|c|c|c|c}
\hline COMPOSIÇÃo & ÁGUA (L) & $\begin{array}{c}\text { CIMENTO } \\
(\mathbf{K g})\end{array}$ & $\begin{array}{c}\text { ÁGREGADO } \\
\text { GRAÚDO } \\
(\mathbf{K g})\end{array}$ & AREIA (Kg) & $\begin{array}{c}\text { SERRAGEM } \\
\mathbf{( K g )}\end{array}$ & $\begin{array}{c}\text { Ś́LICA } \\
(\mathbf{K g})\end{array}$ \\
\hline Referência & 4,00 & 8,00 & 4,00 & 4,00 & - & - \\
\hline S 5\% & 4,00 & 8,00 & 4,00 & 3,80 & 0,20 & - \\
\hline S 7,5\% & 4,00 & 8,00 & 4,00 & 3,70 & 0,30 & - \\
\hline S 10\% & 4,00 & 8,00 & 4,00 & 3,60 & 0,40 & - \\
\hline SS 5\% & 4,00 & 7,20 & 4,00 & 3,80 & 0,20 & 0,80 \\
\hline SS 7,5\% & 4,00 & 7,20 & 4,00 & 3,70 & 0,30 & 0,80 \\
\hline SS 10\% & 4,00 & 7,20 & 4,00 & 3,60 & 0,40 & 0,80 \\
\hline
\end{tabular}

$\mathrm{S}=$ Serragem; $\mathrm{SS}=$ Serragem + Sílica

\subsection{Confecção dos corpos de prova}

Os materiais a serem utilizados em cada traço foram pesados em balança com precisão de $0,05 \mathrm{~g}$ e misturados em betoneira com capacidade de 1451 .

A adição dos insumos na betoneira obedeceu a seguinte ordem: i) todo o agregado graúdo e metade da água necessária; ii) adição do cimento (com ou sem a sílica), misturandoos por um minuto; e iii) adição do agregado miúdo e do restante da água, misturando-os por mais quatro minutos.

\subsection{Ensaios Slump Test}

A trabalhabilidade dos concretos foi medida por meio do ensaio de slump test, seguindo os procedimentos descritos na NBR NM 67 (ABNT, 1998).

Para o ensaio foi utilizada uma haste de adensamento, um tronco de cone com $30 \mathrm{~cm}$ de altura, $10 \mathrm{~cm}$ de diâmetro superior e $20 \mathrm{~cm}$ de diâmetro na parte inferior e uma placa plana e lisa onde foi apoiada a base do cone. O tronco de cone e a chapa de metal foram devidamente umedecidos. A chapa foi então posicionada em um local firme e plano e, com o maior diâmetro do tronco cônico sobre a chapa metálica, deu-se sequência ao ensaio, com os pés apoiados no tronco. O molde foi então preenchido em três camadas iguais e sucessivas, aplicando em cada uma, 25 golpes com a haste de aço. Com o cone completamente preenchido, fez-se a desmoldagem cuidadosa para que não houvesse vibrações e, posteriormente, mediu-se a diferença de altura do Tronco de Cone com o concreto abatido.

\subsection{Moldagem e cura}

As moldagens dos corpos de prova foram realizadas após finalização do slump test e respeitou as prescrições da NBR 5738 (ABNT, 2015). Desta forma, antes de iniciar o processo de moldagem, as formas foram devidamente untadas com óleo e colocadas sobre uma superfície plana. Em seguida, foi preenchida a forma de concreto, dividindo em duas camadas iguais, sendo adensados com uma haste e aplicando 12 golpes para cada camada.

Após a moldagem ser feita, com a finalidade de curar os corpos de prova, nas primeiras 24 horas foram utilizadas toalhas úmidas, encobrindo os moldes para que diminuísse a perda de umidade por evaporação para o ambiente. Posteriormente a esse período, estes foram desmoldados e colocados em recipientes, imersos por água saturada com cal hidratada por um período de 113 dias. O tempo de cura foi prolongado além dos convencionais 28 dias para possibilitar uma análise mais confiável acerca da durabilidade do material. 


\subsection{Ensaio de absorção de água por capilaridade}

O ensaio de absorção por capilaridade obedeceu às prescrições da NBR 9779 (ABNT, 2012). Após completar os 113 dias, os corpos de prova foram retirados dos recipientes com água e previamente secos à temperatura ambiente durante 24 horas para retirada do excesso superficial de água. Depois disso, foram colocados em estufa até a constância de massa em 72 horas, a uma temperatura de $35^{\circ} \mathrm{C}$, para completa secagem antes do início do ensaio.

Após a retirada da estufa, para que não houvesse contato lateral com a água do recipiente, os corpos de prova foram envolvidos lateralmente por uma fita metálica e pesados para a obtenção da massa inicial.

Para garantir que a face inferior do corpo de prova estivesse completamente em contato com a água, foi utilizado uma fina camada de algodão saturada de água, servindo como base (Figura 1). Com os corpos de prova submersos nessa lâmina de água, suas massas foram aferidas com uma balança de precisão, após 3, 6, 24, 48 e 72 horas de contato com a água.

Figura 1 - Corpos de prova em contato com algodão saturado

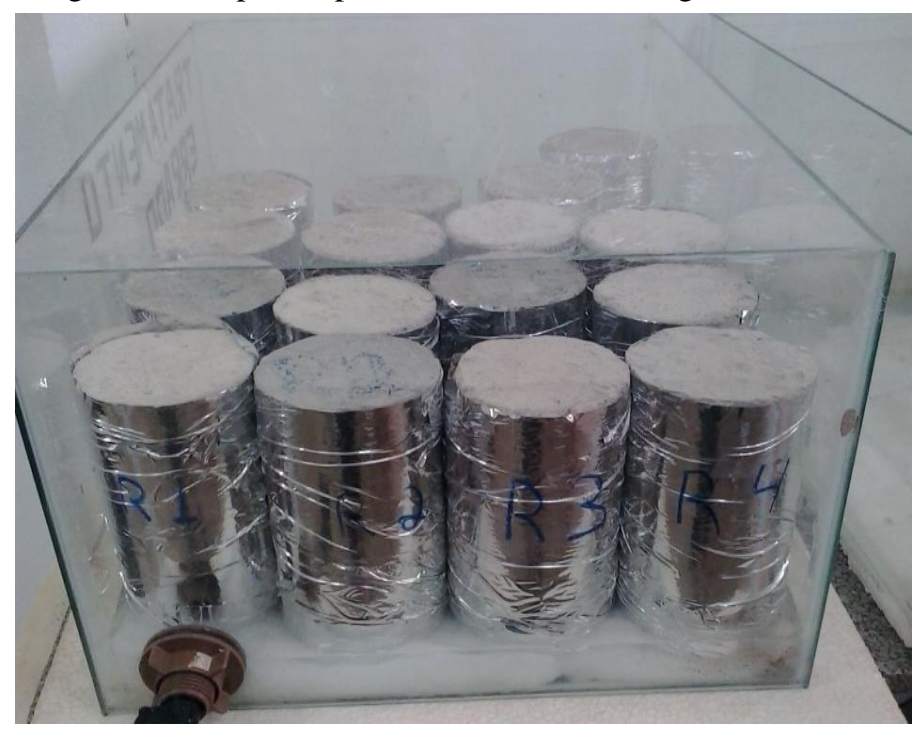

O cálculo da absorção foi realizado por meio da expressão dada pela Equação 1 $\left(\mathrm{g} / \mathrm{cm}^{2}\right)$, em que a diferença de massas deve ser dividida pela área da seção transversal:

$$
C=\frac{A-B}{S}
$$

em que $\mathrm{C}$ é a absorção de água por capilaridade, em g/ $\mathrm{cm}^{2}$; A massa do corpo de prova que permanece com uma das faces em contato com a água durante um período de tempo especificado, em g; B a massa do corpo de prova seco, em g; e, S a área da seção transversal, $\mathrm{em} \mathrm{cm}$.

\subsection{Ensaio de compressão simples}

O ensaio de compressão simples obedeceu a norma NBR 5739 (ABNT, 2018b). Assim sendo, foi utilizado uma prensa hidráulica da marca e modelo Contenco 150T. Todos os corpos de prova tiveram suas faces regularizadas com a ajuda de uma retífica faceadora de corpo de prova. Para a obtenção da tensão resistida pelo concreto, foi utilizada a Equação 2 indicada na sequência (ABNT, 2007): 
Massarotto, Lucas; et al; Caracterização mecânica e reológica de concretos com resíduos de madeira e sílica ativa. E\&S - Engineering and Science, 2019, 8:2.

$$
F c=\frac{4 \times F}{\left(3,14 \times D^{2}\right)}
$$

em que Fc é a Resistência à compressão, em MPa; F a Força máxima alcançada, em N; e, D o Diâmetro da seção transversal, em mm.

\section{RESULTADOS E DISCUSSÕES}

A Tabela 3 apresenta os resultados obtidos do ensaio de slump test. Verifica-se que com o aumento do teor de substituição de areia por serragem, o concreto se torna mais fluído e que a substituição de cimento por $10 \%$ de sílica ocasiona a diminuição da fluidez para os traços equivalentes. Isso ocorre porque a elevação do teor de serragem ocasiona o aumento do teor de orgânicos do resíduo de serragem no material resultante, funcionando como um retardador natural de pega. Em contrapartida, quando é adicionada a sílica, a mesma absorve mais água para a mesma relação água/material cimentício utilizado, o que influencia a trabalhabilidade do produto final.

Tabela 3 - Resultados obtidos com o ensaio de slu
\begin{tabular}{l|l}
\hline COMPOSIÇÃOO & SLUMP TEST $(\mathrm{cm})$ \\
\hline Referência & 22,5 \\
\hline S 5\% & 25 \\
\hline S 7,5\% & 23,5 \\
\hline S 10\% & 23 \\
\hline SS 5\% & 22 \\
\hline SS 7,5\% & 20,5 \\
\hline SS 10\% & 20,5 \\
\hline
\end{tabular}

Nas Figura 2 e 3 são apresentados os resultados obtidos no ensaio de absorção por capilaridade. Verifica-se que o concreto com resíduo de madeira absorveu menor quantidade de água que o concreto de referência.

Os dados encontrados corroboram com pesquisa realizada por Garcez, Santos e Gatto (2013), a qual explica que o aumento do percentual de substituição da areia por serragem ocasiona redução na resistência do concreto. O estudo, em termos gerais, indicou que a resistência dos traços com substituição é inferior ao traço de referência. Por outro lado, observaram que as peças ficaram mais leves.

Figura 2 - Curvas de absorção por capilaridade nos concretos com resíduos de serragem

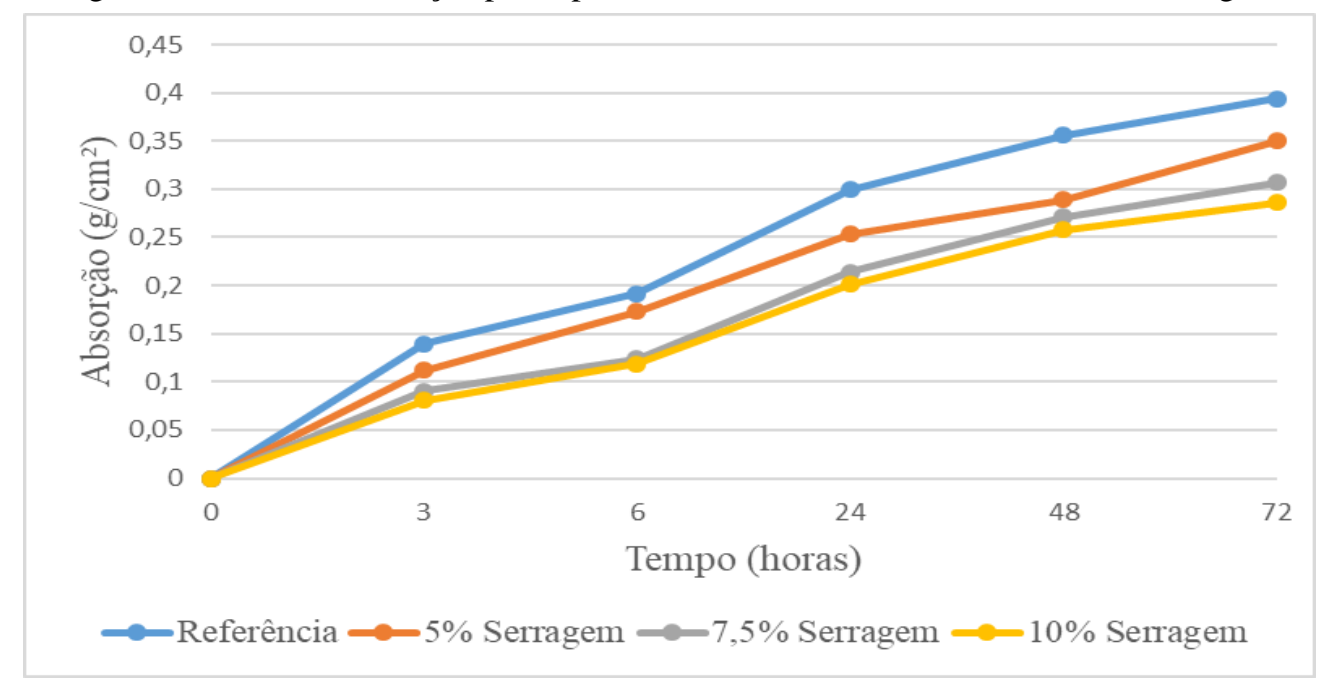


Massarotto, Lucas; et al; Caracterização mecânica e reológica de concretos com resíduos de madeira e sílica ativa. E\&S - Engineering and Science, 2019, 8:2.

Figura 3 - Curvas de absorção por capilaridade nos concretos com serragem e sílica ativa

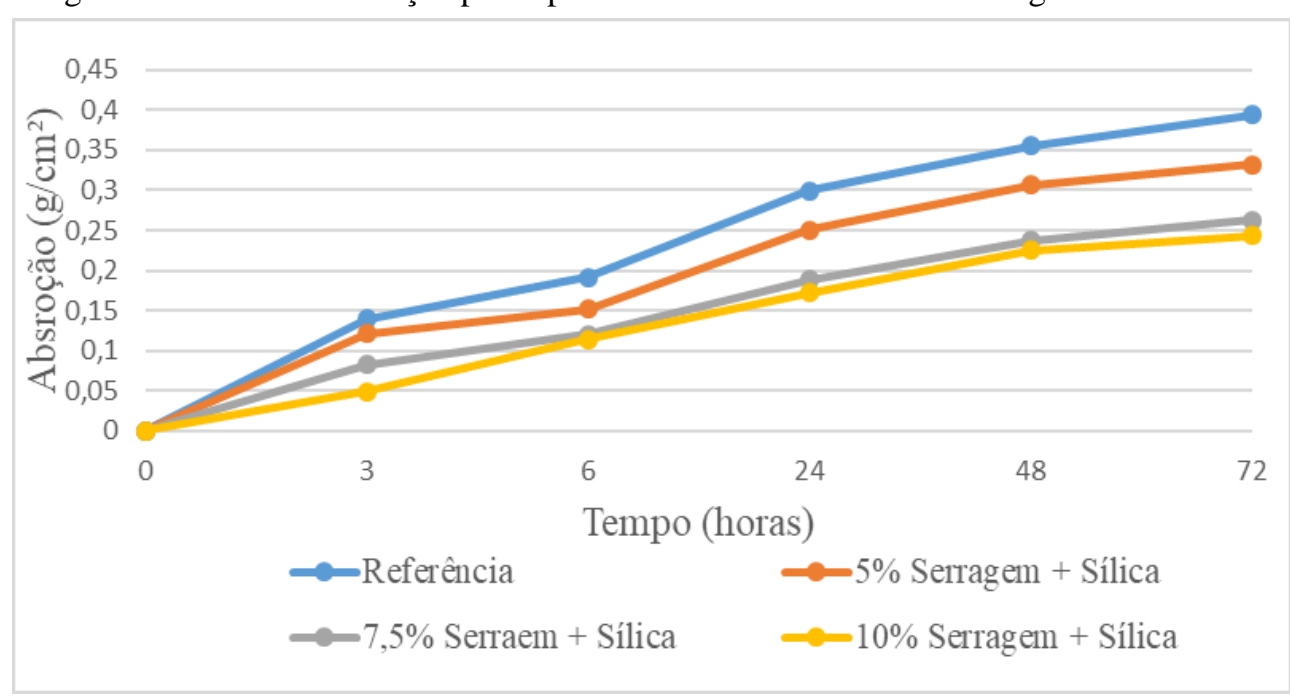

Ao se comparar os concretos dosados com serragem e serragem+silica, é possível observar que a sílica apresenta um comportamento denominado "efeito microfíler" e "efeito pozolânico", uma vez que os tamanhos das partículas são inferiores às do cimento (aproximadamente $0,1 \mu \mathrm{m}$ ). Desta forma, é gerado efeito de empacotamento, reduzindo a porosidade da matriz e influenciando a absorção de água conforme pode ser constatado na Figura 4.

Figura 4 - Diferença de absorção entre os concretos com e sem sílica ativa

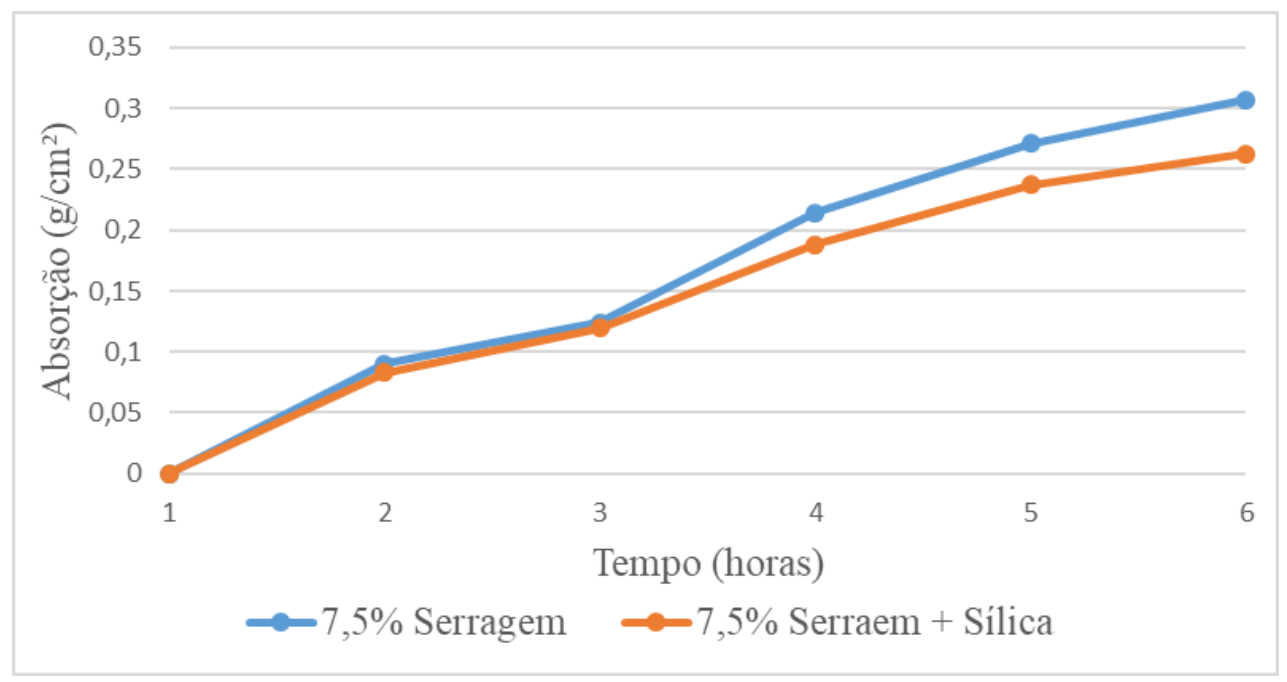

No estudo conduzido por Herman et al. (2016), utilizando modelo analítico de empacotamento de partículas (Compressible Packing Model), verificou-se que a densidade de empacotamento na condição úmida em concreto com substituição parcial por sílica ativa apresentou um valor menor que o cimento devido ao tamanho menor de suas partículas, que tendem a se aglomerar e formar redes de canais abertos entre as partículas de sílica aglomerada.

Na Tabela 4 são apresentados os resultados de resistência à compressão simples dos concretos com os diferentes traços estudados. Por meio dela, é possível verificar, que a substituição da serragem por areia (agregado miúdo), também afetou a resistência, visto que os resíduos de serragem são, naturalmente, mais leves e menos resistentes que a areia. 
Tabela 4 - Resistência média à compressão do concreto simples

\begin{tabular}{l|l}
\hline COMPOSIÇÃO & fck $(\mathrm{MPa})$ \\
\hline Referência & 29,85 \\
\hline S 5\% & 21,68 \\
\hline S 7,5\% & 26,06 \\
\hline S 10\% & 27,5 \\
\hline SS 5\% & 23,71 \\
\hline SS 7,5\% & 26,71 \\
\hline SS 10\% & 30,43 \\
\hline
\end{tabular}

Em relação aos concretos com sílica, nota-se que a resistência à compressão em relação aos mesmos concretos com serragem e sem sílica, é maior. Isto ocorre, pois, apesar da serragem diminuir a resistência do concreto, a sílica por sua vez, proporciona $o$ desencadeando das reações pozolânicas, que fazem com que estes concretos sejam mais resistentes do que aqueles que só possuem a serragem, Carmo e Portella (2008) relatam que no estado endurecido do concreto, a adição de sílica contribui com o ganho de resistência mecânica e que a porcentagem ótima de sílica ativa, no traço de concreto, está entre $7 \%$ a $10 \%$.

No mesmo sentido, Isaia (1995) verificou que o efeito da pozolana na mistura do concreto contribui com a minimização dos poros no concreto, corroborando com os estudos apresentados e os resultados obtidos nesta pesquisa.

Em estudo realizado por Bianchini (2010) evidenciou-se que, para a produção de concretos de alta resistência (aos 28 dias de idade ou superior), o aumento dos teores de sílica ativa empregados, dentro da faixa estudada, gerou aumentos na resistência à compressão se comparado com o concreto de referência.

Já em pesquisa realizada por Medeiros et al. (2013), o uso da sílica ativa em substituição ao cimento, reduziu a carga passante no ensaio de migração de cloretos em 85$88 \%$ e, portanto, evidenciando a grande eficiência da sílica ativa para produzir concretos duráveis em regiões altamente influenciadas pela maresia. Segundo o autor, o tempo de vida útil de serviço aumentou em $440 \%$ quando houve adição da sílica ativa. Este fato demonstra que a sílica ativa possui outros efeitos que estão relacionados, também, à diminuição da permeabilidade do concreto.

Entre os traços pesquisados, os concretos confeccionados com $10 \%$ de substituição da areia por serragem e $10 \%$ do cimento por sílica, apresentaram os melhores desempenhos. Aqueles com apenas substituição com serragem, apresentaram resistência média 8,5\% inferior ao de referência. Entretanto, com adição de sílica, a resistência foi superior em $2 \%$ se comparado com o de referência.

Ainda, ambos os traços apresentaram menor índice de absorção de água do que o de referência. Portanto, verifica-se que a adição de sílica ativa nas misturas de concreto gera um efeito benéfico para as misturas pesquisadas quanto à resistência.

\section{CONCLUSÕES}

O presente estudo objetivou analisar os efeitos das substituições parciais de serragem e sílica ativa em misturas do concreto. Foi possível comprovar que o aumento do teor de resíduos de serragem resultou em um aumento da trabalhabilidade dos concretos. Ainda, houve a redução da absorção por capilaridade comparado com o concreto referência. Por outro lado, a adição de sílica ativa ocasionou a diminuição da trabalhabilidade e, também, a redução de absorção de água por capilaridade, superou os demais traços de concretos pesquisados.

Quanto ao concreto com substituição somente com serragem, quanto maior a adição 
Massarotto, Lucas; et al; Caracterização mecânica e reológica de concretos com resíduos de madeira e sílica ativa. E\&S - Engineering and Science, 2019, 8:2.

deste, menor foi a absorção, menor resistência à compressão.

Quanto ao concreto com adição de sílica e serragem, houve o aumento na resistência e menor absorção de água à medida que a porcentagem destes eram aumentados.

Nota-se que em relação aos concretos com substituição de $10 \%$ de cimento por sílica ativa, foi possível elevar a resistência dos concretos com adição de serragem sem o uso adicional de sílica além dos $10 \%$. Verificou-se, também, menor absorção de água, comprovando-se o efeito benéfico da adição de sílica nas misturas.

Isto posto, verifica-se que a problematização foi respondida, pois houve, de fato, consideráveis alterações nos desempenhos mecânicos e reológicos quando realizadas substituições parciais de areia e cimento por serragem e sílica ativa, corroborando com a hipótese inicial levantada no planejamento da pesquisa.

Ainda, a partir deste estudo, é possível identificar nova problematização, por exemplo: quais são as causas que levam à perda de resistência do concreto pela adição de serragem e sílica ativa? Assim, com a busca de ideias que possam minimizar ou maximizar tais efeitos, é possível identificar materiais e misturas potenciais para aplicação na construção civil.

\section{REFERENCIAS}

ASSOCIAÇÃO BRASILEIRA DE CIMENTO PORTLAND. Pesquisa inédita e exclusiva revela cenário do mercado brasileiro de concreto. Jaguaré, 2013. Disponível em: https://www.abcp.org.br/cms/imprensa/noticias/pesquisa-inedita-e-exclusiva-revela-cenariodo-mercado-brasileiro-de-concreto/. Acesso em: 11 jul. 2019.

ASSOCIAÇÃO BRASILEIRA DE EMPRESAS DE LIMPEZA E RESÍDUOS ESPECIAIS. Panorama dos Resíduos Sólidos no Brasil 2014. São Paulo: Abrelpe, 2014. Disponível em: https://edisciplinas.usp.br/pluginfile.php/4389267/mod_resource/content/1/panorama2014.pdf . Acesso em: 11 jul. 2019.

ASSOCIAÇÃO BRASILEIRA DE NORMAS TÉCNICAS. ABNT NBR NM 67: Concreto: Determinação da consistência pelo abatimento de tronco de cone, Rio de Janeiro, 1998.

NBR 9779: Argamassa e concreto endurecidos: Determinação da absorção de água por capilaridade, Rio de Janeiro, 2012.

NBR 5738: Concreto: Procedimento para moldagem e cura de corpos de prova, Rio de Janeiro, 2015.

NBR 7181: Solo: Análise granulométrica, Rio de Janeiro, 2018.

NBR 5739: Concreto: Ensaio de compressão de corpos de prova cilíndricos, Rio de Janeiro, 2018.

BIANCHINI, M. Análise da influência dos teores de sílica ativa na produção de concretos de alta resistência em central dosadora de concreto. 2010. Dissertação (Mestrado). 148f. Pós-Graduação em Construção Civil, Universidade Federal do Paraná, 2010.

CARMO, J. B. M.; PORTELLA, K. F. Estudo comparativo do desempenho mecânico da sílica ativa e do metacaulim como adições químicas minerais em estruturas de concreto. 
Massarotto, Lucas; et al; Caracterização mecânica e reológica de concretos com resíduos de madeira e sílica ativa. E\&S - Engineering and Science, 2019, 8:2.

Cerâmica, $\quad$ v. $\quad$ 54, n. $\quad 331, \quad$ p.309-318, 2008. http://dx.doi.org/10.1590/S036669132008000300007

BRASIL. Ministério de Minas e Energia. Conselho Nacional Do Meio Ambiente. Resolução n. 307 - Estabelece diretrizes, critérios e procedimentos para a gestão dos resíduos da construção civil, Brasília, 2002, 7p.

DIPROTEC. Sílica Ativa (Microssílica). Paraná, 2016. Disponível em: http://www.diprotec.com.br/produto/silica-ativa-microssilica/. Acesso em: 11 jul. 2019.

GARCEZ, M. R; SANTOS, T; GATTO, D. A. Avaliação das propriedades físicas e mecânicas de concretos pré-moldados com adição de serragem em substituição ao agregado $\begin{array}{llllllll}\text { miúdo. Ciência } \quad \text { \& } & \text { Engenharia, v. } & \text { 22, } & \text { n. } & 2, & \text { p.95-104, }\end{array}$ https://doi.org/10.14393/19834071.2013.23666

HERMANN, A.; LANGARO, E. A.; SILVA, S. H. L.; KLEIN, N. S. Particle packing of cement and silica fume in pastes using an analytical model. Revista IBRACON de Estruturas e Materiais. v. 9, n. 1, p.48-65, 2016. http://dx.doi.org/10.1590/S198341952016000100004

ISAIA, G. C. Efeitos de misturas binarias e ternarias de pozolanas em concreto de elevado desempenho: um estudo de durabilidade com vistas a corrosão da armadura. 1995. Tese (Doutorado em Engenharia). 240p. Escola Politécnica, Universidade de São Paulo, São Paulo, 1995.

MEDEIROS, M. H. F.; GOBBI A.; GROENWOLD, J. A; HELENE, P. Previsão da vida útil de concreto armado de alta resistência com adição de metacaulim e sílica ativa em ambientes $\begin{array}{llllllll}\text { marinhos. Revista Escola de Minas, v. } & \text { 66, n. } 1, & \text { p.59-65, } 2013 .\end{array}$ http://dx.doi.org/10.1590/S0370-44672013000100008

SANTOS, R. C. Serragem substitui materiais da construção civil. Jornal da Unicamp, 2014. Disponível em: <https://doutorbloco.com.br/serragem-substitui-materiais-daconstrucao-civil/>. Acesso em: 21 mar. 2019.

SENAI. Gestão de resíduos na construção civil: Redução, reutilização e reciclagem. Brasília: SENAI, 2013. Disponível em: http://www.fieb.org.br/bancafieb/livros. Acesso em: 11 jul. 2019.

SINDICATO NACIONAL DA INDÚSTRIA DO CIMENTO. Resultados Preliminares de Abril 2019. Rio de Janeiro, 2019. Disponível em: <http://snic.org.br/numeros-resultadospreliminares-ver.php?id=36>. Acesso em: 24 jun. 2019.

TECNOSIL. Sílica Ativa. Itupeva, 2018. Disponível em: <https://www.tecnosilbr.com.br/silica-ativa/>. Acesso em: 24 jun. 2019. 